\title{
Uptake and Release of Glucose by the Human Kidney Postabsorptive Rates and Responses to Epinephrine
}

Michael Stumvoll, ${ }^{*}$ Udaya Chintalapudi, ${ }^{\S}$ Gabriele Perriello, ${ }^{\star}$ Stephen Welle, ${ }^{\star \star}$ Oscar Gutierrez, ${ }^{\S}$ and John Gerich* University of Rochester School of Medicine, Departments of $*$ Medicine, ${ }^{\ddagger}$ Physiology, and ${ }^{\S}$ Radiology, Rochester, New York 14642

\begin{abstract}
Despite ample evidence that the kidney can both produce and use appreciable amounts of glucose, the human kidney is generally regarded as playing a minor role in glucose homeostasis. This view is based on measurements of arteriorenal vein glucose concentrations indicating little or no net release of glucose. However, inferences from net balance measurements do not take into consideration the simultaneous release and uptake of glucose by the kidney. Therefore, to assess the contribution of release and uptake of glucose by the human kidney to overall entry and removal of plasma glucose, we used a combination of balance and isotope techniques to measure renal glucose net balance, fractional extraction, uptake and release as well as overall plasma glucose appearance and disposal in 10 normal volunteers under basal postabsorptive conditions and during a 3-h epinephrine infusion. In the basal postabsorptive state, there was small but significant net output of glucose by the kidney $\left(66 \pm 22 \mu \mathrm{mol} \cdot \mathrm{min}^{-1}, P=0.016\right)$. However, since renal glucose fractional extraction averaged $2.9 \pm 0.3 \%$, there was considerable renal glucose uptake $\left(2.3 \pm 0.2 \mu \mathrm{mol} \cdot \mathrm{kg}^{-1}\right.$. $\mathrm{min}^{-1}$ ) which accounted for $20.2 \pm 1.7 \%$ of systemic glucose disposal $\left(11.4 \pm 0.5 \mu \mathrm{mol} \cdot \mathrm{kg}^{-1} \cdot \mathrm{min}^{-1}\right)$. Renal glucose release $\left(3.2 \pm 0.2 \mu \mathrm{mol} \cdot \mathrm{kg}^{-1} \cdot \mathrm{min}^{-1}\right)$ accounted for $27.8 \pm 2.1 \%$ of systemic glucose appearance $(11.4 \pm 0.5 \mu \mathrm{mol}-$ $\left.\cdot \mathrm{kg}^{-1} \cdot \min ^{-1}\right)$. Epinephrine infusion, which increased plasma epinephrine to levels observed during hypoglycemia $(3722 \pm 453 \mathrm{pmol} / \mathrm{liter})$ increased renal glucose release nearly twofold $\left(5.2 \pm 0.5\right.$ vs $2.8 \pm 0.1 \mathrm{~mol} \cdot \mathrm{kg}^{-1} \cdot \mathrm{min}^{-1}, P$ $=0.01$ ) so that at the end of the infusion, renal glucose release accounted for $\mathbf{4 0 . 3} \pm \mathbf{5 . 5 \%}$ of systemic glucose appearance and essentially all of the increase in systemic glucose appearance. These observations suggest an important role for the human kidney in glucose homeostasis. (J. Clin. Invest. 1995. 96:2528-2533.) Key words: liver • kidney • gluconeogenesis $\cdot$ glucose production $\cdot$ glucose utilization
\end{abstract}

Address correspondence to John E. Gerich, MD, University of Rochester School of Medicine, 601 Elmwood Avenue, Box MED/CRC, Rochester, NY 14642. Phone 716-275-5295; FAX: 716-461-4737.

Received for publication 14 June 1995 and accepted in revised form 23 August 1995.

J. Clin. Invest.

(c) The American Society for Clinical Investigation, Inc.

0021-9738/95/11/2528/06 \$2.00

Volume 96, November 1995, 2528-2533

\section{Introduction}

It has long been known from in vitro experiments and studies in animals that the kidney can both produce and use appreciable amounts of glucose (1-3). Nevertheless, the human kidney is generally regarded as playing a minor role in glucose homeostasis $(4-6)$. This view is largely based on net balance experiments finding no significant difference in arterial and renal vein glucose concentrations (7-10) except in patients with respiratory acidosis (7) and in obese individuals after prolonged starvation (11).

However, the net balance approach does not take into consideration simultaneous release and uptake of glucose by an organ. These are distinct processes in liver and kidney subject to separate regulation and occurring in different locations in these tissues $(1-3,12,13)$. By merely representing the difference between uptake and release of a substrate, net balance measurements cannot evaluate the contribution of an organ to the entry and removal of a substrate from the systemic circulation. Moreover, inferences based on net balance measurements may lead to an underestimation of the role of an organ in the overall metabolism of a substrate.

For example, with isotope dilution determination of systemic glucose flux, entry of glucose into the circulation is quantified by the dilution of the plasma glucose tracer concentration by unlabeled glucose released into the circulation (14). If the kidney were to take up and release glucose at equal rates, there would be no arterio-renal venous glucose difference, and net glucose balance would be zero. Nevertheless, release of unlabeled glucose into the circulation by the kidney would dilute the plasma glucose tracer concentration and contribute to the isotopic estimation of glucose entry into the circulation. Similar considerations hold for the contribution of the kidney to removal of glucose from the circulation as determined isotopically (14).

A combination of net balance and isotopic techniques is necessary to assess individually the uptake and release of a substrate by an organ $(15,16)$. Two recent studies $(17,18)$ using this approach in dogs indicate that the kidney may be responsible for $>20 \%$ of glucose entry into the circulation and $>30 \%$ of glucose removal from the circulation under postabsorptive conditions and that renal glucose metabolism is sensitive to hormonal regulation. Comparable studies have not been conducted in humans (19).

We therefore undertook the present studies to assess the contribution of the kidney to systemic glucose flux in normal postabsorptive humans and to determine whether release of glucose by the human kidney was under hormonal control. For this purpose we used a combination of net balance and isotopic methods and infused volunteers with epinephrine. Our results indicate that in postabsorptive humans $(a)$ renal glucose release 
accounts for approximately $25 \%$ of all glucose entering the circulation; $(b)$ renal glucose uptake accounts for $\sim 20 \%$ of glucose removed from the circulation; and $(c)$ that physiologic concentrations of epinephrine stimulate renal glucose release. These observations thus provide evidence that the human kidney may play an important role in glucose homeostasis.

\section{Methods}

Subjects. Informed written consent was obtained from 10 normal volunteers ( 9 men, 1 woman) after the protocol had been approved by our local Institutional Review Board. The subjects were $26 \pm 2$ $($ mean \pm SEM) years of age, weighed $80 \pm 3 \mathrm{~kg}$ (body mass index $24.9 \pm 0.8 \mathrm{~kg} / \mathrm{m}^{2}$ ), had normal glucose tolerance tests according to World Health Organization criteria (21) and no family history of diabetes. For $3 \mathrm{~d}$ before the study, all had been on a weight maintaining diet containing at least 200 grams carbohydrate and had abstained from alcohol.

Protocol. Subjects were admitted to the University of Rochester General Clinical Research Center between 6:00 and 7:00 p.m. in the evening before experiments; they consumed a standard meal ( $10 \mathrm{kcal} /$ $\mathrm{kg}, 50 \%$ carbohydrate, $35 \%$ fat, and $15 \%$ protein) between $6: 00$ and 8:00 p.m. and were fasted overnight until experiments were completed.

At 5:30 a.m., an antecubital vein was cannulated and a primedcontinuous infusion of $\left[6-{ }^{3} \mathrm{H}\right]$ glucose $(30 \mu \mathrm{Ci}, 0.3 \mu \mathrm{Ci} / \mathrm{min}$; Amersham International, Amersham, UK) was started. As a pilot study for a different protocol, subjects were also infused with either $\left[\mathrm{U}-{ }^{14} \mathrm{C}\right]$ glutamine and $\left[3-{ }^{13} \mathrm{C}\right]$ alanine, $\left[\mathrm{U}-{ }^{14} \mathrm{C}\right]$ glycerol and $\left[3-{ }^{13} \mathrm{C}\right]$ lactate, or [ring- $\left.\mathrm{d}_{5}\right]$ phenylalanine and [ring- $\mathrm{d}_{4}$ ] tyrosine. Between 8:00 and 9:00 a.m. a right $(n=8)$ or left $(n=2)$ renal vein was catheterized through the right femoral vein under fluoroscopy and the position of the catheter tip was ascertained by injecting a small amount of iodinated contrast material. The catheter was then continuously infused with a heparinized saline solution $(5.6 \mathrm{U} / \mathrm{min})$ to maintain patency.

At 9:00 a.m. a dorsal hand vein was cannulated and kept in a thermoregulated Plexiglass box at $65^{\circ} \mathrm{C}$ for sampling arterialized venous blood (22) and an antecubital venous infusion of $p$-aminohippuric acid (12 $\mathrm{mg} / \mathrm{min}$ ) was started for determination of renal blood flow. After allowing $\sim 4 \mathrm{~h}$ to achieve isotopic steady state, three blood samples were collected simultaneously from the dorsal hand vein and the renal vein at 30-min intervals $(-60,-30,0 \mathrm{~min})$ for determination of glucose (in triplicate), insulin, glucagon, epinephrine and $p$-aminohippuric acid concentrations and glucose specific activity. At $0 \mathrm{~min}$, a continuous infusion of either epinephrine $\left(50 \mathrm{ng} \cdot \mathrm{kg}^{-1} \cdot \mathrm{min}^{-1}\right)(n=6)$ or normal saline $(n=4)$ was started via the antecubital infusion line and blood was collected as described above at 30-min intervals for $3 \mathrm{~h}$.

Analytical procedures. Blood samples for glucose concentrations and specific activity (SA) were collected in oxalate-fluoride tubes, for epinephrine in EGTA tubes and for insulin and glucagon in EDTA tubes containing a protease inhibitor. Whole blood glucose was immediately determined in triplicate with a glucose analyzer (Yellow Springs Instrument $\mathrm{Co}$., Yellow Springs, $\mathrm{OH}$ ). For other determinations, samples were placed immediately in a $4^{\circ} \mathrm{C}$ ice bath and plasma was separated within 30 min by centrifugation at $4^{\circ} \mathrm{C}$. Plasma $\left[{ }^{3} \mathrm{H}\right]$ glucose $S A$ was determined in duplicate by high performance liquid chromatography (HPLC) (22). Since preliminary studies indicated that HPLC-determined SA's on whole blood and plasma extracts were identical and since plasma was easier to process, we used plasma for specific activity measurements. The circulating concentrations of tritiated glucose were calculated as the product of their SA and whole blood glucose concentration. Plasma insulin and glucagon concentrations were determined by standard radioimmunoassays as previously described (23). Plasma epinephrine concentrations were determined by a radioenzymatic method (24) and plasma $p$-aminohippuric acid concentration by a colorimetric method (25).

Calculations. Renal plasma flow (RPF) was determined by the $p$ aminohippuric acid clearance technique (26) and renal blood flow
Table I. Arterial and Renal Vein Glucose Concentrations and Specific Activities in Normal Postabsorptive Volunteers*

\begin{tabular}{|c|c|c|c|c|c|c|}
\hline \multirow[b]{2}{*}{ Subject } & \multicolumn{2}{|c|}{$\begin{array}{c}\text { Glucose } \\
\text { concentration } \\
(\mathrm{mmol} / \mathrm{liter})\end{array}$} & \multicolumn{2}{|c|}{$\begin{array}{l}{\left[^{3} \mathrm{H}\right] \text { Glucose- }} \\
\text { specific activity } \\
(\mathrm{dpm} / \mu \mathrm{mol})\end{array}$} & \multicolumn{2}{|c|}{$\begin{array}{l}{\left[{ }^{3} \mathrm{H}\right] \text { Glucose }} \\
\text { concentration" } \\
(\mathrm{dpm} / \mathrm{ml})\end{array}$} \\
\hline & Artery & Renal vein & Artery & Renal vein & Artery & Renal vein \\
\hline 1 & 4.01 & 4.08 & 739 & 709 & 2966 & 2895 \\
\hline 2 & 3.97 & 3.99 & 709 & 680 & 2966 & 2895 \\
\hline 3 & 4.38 & 4.55 & 726 & 683 & 3177 & 3109 \\
\hline 4 & 4.68 & 4.68 & 714 & 681 & 3338 & 3186 \\
\hline 5 & 4.08 & 4.11 & 353 & 335 & 1443 & 1376 \\
\hline 6 & 4.39 & 4.39 & 776 & 757 & 3404 & 3322 \\
\hline 7 & 4.16 & 4.20 & 708 & 688 & 2950 & 2893 \\
\hline 8 & 4.70 & 4.72 & 531 & 514 & 2495 & 2422 \\
\hline 9 & 4.55 & 4.60 & 443 & 425 & 2013 & 1956 \\
\hline 10 & 4.10 & 4.16 & 724 & 697 & 2967 & 2898 \\
\hline Mean & 4.30 & 4.35 & 642 & 617 & 2756 & 2677 \\
\hline \pm SEM & 0.08 & 0.08 & 44 & 42 & 185 & 181 \\
\hline$P$ vs Arterial & & 0.016 & & 0.001 & & 0.001 \\
\hline
\end{tabular}

* Mean of three values performed in duplicate or triplicate; ${ }^{\ddagger}$ whole blood; "plasma; and "calculated as product of whole blood glucose concentration and plasma glucose specific activity.

(RBF) was calculated as RPF/( 1 - Hematocrit). Fractional extraction (FX) of glucose across the kidney was calculated as $\left(\left[6-{ }^{3} \mathrm{H}\right]\right.$ glucose $\mathrm{SA}_{\text {art }} \times[\text { glucose }]_{\text {art }}-\left[6-{ }^{3} \mathrm{H}\right]$ glucose $\left.\mathrm{SA}_{\text {renal vein }} \times[\text { glucose }]_{\text {renal vein }}\right) /$ $\left.\left(\left[6-{ }^{3} \mathrm{H}\right] \text { glucose } \mathrm{SA}_{\text {ar }} \times \text { [glucose }\right]_{\text {art }}\right)(15)$. Renal glucose uptake (RGU) was calculated as RBF $\times$ [glucose $]_{\mathrm{ar}} \times \mathrm{FX}$, and renal glucose net balance (NB) as RBF $\times\left([\text { glucose }]_{\text {art }}-[\text { [glucose }]_{\text {renal vein }}\right)(15)$. Renal glucose release (RGR) was calculated as RGU - NB (15).

Overall appearance and removal of glucose from the circulation was determined using steady state equations under basal conditions (14) and subsequently during infusion of epinephrine or saline using non-steady state equations of DeBodo et al. (27). A volume of distribution of 200 $\mathrm{ml} / \mathrm{kg}$ and a pool fraction of 0.65 were used. It was assumed that the liver is the only organ other than the kidney capable of adding glucose to the circulation, and therefore hepatic glucose release (HGR) was calculated as the difference between the overall appearance of glucose and renal glucose release. Use of monocompartmental equations can be associated with as much as a $20 \%$ underestimation of the rate of appearance of glucose under conditions in which there are large and rapid changes in plasma glucose specific activity such as during hyperinsulinemic clamp experiments $(28,29)$. Underestimation of overall glucose appearance during the epinephrine infusions due to deficiencies of monocompartmental equations would result in underestimations of HGR as calculated above. However, since isotopic steady state was approximated during the last $30 \mathrm{~min}$ of the epinephrine infusion when statistical comparisons were made, deficiencies of these equations would have minimal, if any, influence.

Statistical analysis. Unless stated otherwise, data are expressed as mean \pm SEM. Paired two tailed Student's $i$ tests were used to compare arterial and renal vein glucose concentrations and specific activities. Nonpaired two tailed Student's $t$ tests were used to compare data obtained during saline and epinephrine infusions. A $P$ value less than 0.05 was considered to be statistically significant.

\section{Results}

Postabsorptive state (Tables I-III). Arterial and renal vein glucose concentrations and $\left[{ }^{3} \mathrm{H}\right]$ glucose specific activities were stable over the 1-h baseline sampling period (data not shown) 
Table II. Renal Blood Flow and Glucose Fractional Extraction, Net Balance, Uptake, and Release in Normal Postabsorptive Volunteers*

\begin{tabular}{cccccc}
\hline Subject & $\begin{array}{c}\text { Renal } \\
\text { blood flow }\end{array}$ & $\begin{array}{c}\text { Net } \\
\text { balance }\end{array}$ & $\begin{array}{c}\text { Fractional } \\
\text { extraction }\end{array}$ & Uptake & Release \\
\hline & ml/min & $\mu$ mol/min & $\%$ & $\mu$ mol/min & $\mu$ molmin \\
1 & 1392 & -99 & 2.4 & 133 & 231 \\
2 & 2030 & -48 & 3.5 & 278 & 326 \\
3 & 1512 & -258 & 2.1 & 141 & 398 \\
4 & 907 & 0 & 4.6 & 194 & 194 \\
5 & 1446 & -45 & 4.7 & 277 & 321 \\
6 & 1585 & -4 & 2.4 & 166 & 170 \\
7 & 1567 & -61 & 1.9 & 127 & 187 \\
8 & 1628 & -20 & 2.9 & 223 & 243 \\
9 & 1191 & -66 & 2.8 & 153 & 219 \\
10 & 1391 & -90 & 2.2 & 123 & 214 \\
Mean & 1465 & -69 & 2.9 & 181 & 250 \\
\pm SEM & 88 & 22 & 0.3 & 18 & 22 \\
& & & & & \\
\hline
\end{tabular}

* Mean of three values performed in duplicate or triplicate.

indicating that isotopic steady state had been achieved. During this period, renal vein glucose concentrations were slightly but significantly greater than arterial concentrations while arterial $\left[{ }^{3} \mathrm{H}\right]$ glucose specific activities and $\left[{ }^{3} \mathrm{H}\right]$ glucose concentrations were greater than renal vein values. These data indicate that there was significant net output of glucose by the kidney coincident with simultaneous uptake and release of glucose by the kidney.

Renal blood flow and renal $\left[{ }^{3} \mathrm{H}\right]$ glucose fractional extraction averaged $1465 \pm 88 \mathrm{ml} / \mathrm{min}$ and $2.9 \pm 0.3 \%$, respectively. Renal glucose net balance, uptake and release were $-69 \pm 22$, $181 \pm 18$ and $250 \pm 22 \mu \mathrm{mol} / \mathrm{min}$, respectively.

Under steady state conditions release of glucose into the circulation and its removal from the circulation approximate

Table III. Rates of Systemic Glucose Turnover, Renal Glucose Release, Hepatic Glucose Release, and Renal Glucose Uptake in Normal Postabsorptive Volunteers*

\begin{tabular}{|c|c|c|c|c|}
\hline Subject & $\begin{array}{l}\text { Systemic glucose } \\
\text { turnover }\end{array}$ & $\begin{array}{l}\text { Renal glucose } \\
\text { release }^{\ddagger}\end{array}$ & $\begin{array}{l}\text { Hepatic glucose } \\
\text { release }^{\ddagger}\end{array}$ & $\begin{array}{c}\text { Renal glucose } \\
\text { uptake }^{\ddagger}\end{array}$ \\
\hline 1 & 10.1 & $3.2(31.3)$ & $6.9(68.9)$ & $1.8(18.0)$ \\
\hline 2 & 11.7 & $4.3(36.4)$ & $7.5(63.6)$ & $3.6(31.0)$ \\
\hline 3 & 10.3 & $4.4(42.5)$ & $5.9(57.5)$ & $1.5(15.0)$ \\
\hline 4 & 12.4 & $3.3(26.5)$ & $9.1(73.5)$ & $3.3(26.5)$ \\
\hline 5 & 14.5 & $4.0(27.8)$ & $10.4(72.2)$ & $3.5(24.0)$ \\
\hline 6 & 9.9 & $2.1(20.9)$ & $7.9(79.1)$ & $2.0(20.4)$ \\
\hline 7 & 11.4 & $2.7(24.0)$ & $8.6(76.0)$ & $1.8(16.2)$ \\
\hline 8 & 10.1 & $2.5(24.9)$ & $7.6(75.1)$ & $2.3(22.8)$ \\
\hline 9 & 12.2 & $2.7(21.8)$ & $9.7(78.2)$ & $1.9(15.2)$ \\
\hline 10 & 10.7 & $2.5(23.2)$ & $8.2(76.8)$ & $1.4(13.4)$ \\
\hline Mean & 11.4 & $3.2(27.8)$ & $8.2(72.2)$ & $2.3(20.2)$ \\
\hline \pm SEM & 0.5 & $0.2(2.1)$ & $0.4(5.9)$ & $0.2(1.7)$ \\
\hline
\end{tabular}

${ }^{*} \mu \mathrm{mol} \cdot \mathrm{kg}^{-1} \mathrm{~min}^{-1} ;{ }^{\ddagger}$ values in parentheses represent the percent of overall systemic glucose release or uptake.
Table IV. Baseline and Responses during Infusion of Epinephrine or Saline (Mean \pm SEM)

\begin{tabular}{|c|c|c|}
\hline & Basal* & Final $30 \mathrm{~min}^{\ddagger}$ \\
\hline \multicolumn{3}{|c|}{ Plasma Epinephrine (pmol/liter) } \\
\hline Saline & $156 \pm 10$ & $138 \pm 7$ \\
\hline Epinephrine & $247 \pm 45$ & $3723 \pm 453$ \\
\hline$P=$ & 0.21 & 0.001 \\
\hline \multicolumn{3}{|c|}{ Blood Glucose (mmol/liter) } \\
\hline Saline & $4.26 \pm 0.14$ & $3.96 \pm 0.15$ \\
\hline Epinephrine & $4.33 \pm 0.10$ & $6.32 \pm 0.49$ \\
\hline$P=$ & 0.74 & 0.02 \\
\hline \multicolumn{3}{|c|}{ Plasma Insulin (pmol/liter) } \\
\hline Saline & $7.8 \pm 1.1$ & $7.5 \pm 0.7$ \\
\hline Epinephrine & $6.0 \pm 0.4$ & $10.6 \pm 1.2$ \\
\hline$P=$ & 0.25 & 0.08 \\
\hline \multicolumn{3}{|c|}{ Plasma Glucagon (ng/liter) } \\
\hline Saline & $135 \pm 21$ & $140 \pm 24$ \\
\hline Epinephrine & $162 \pm 8$ & $173 \pm 9$ \\
\hline$P=$ & 0.36 & 0.33 \\
\hline \multicolumn{3}{|c|}{$\begin{array}{l}\text { Systemic Glucose Appearance } \\
\left(\mu \mathrm{mol} \cdot \mathrm{kg}^{-1} \cdot \mathrm{min}^{-1}\right)\end{array}$} \\
\hline Saline & $11.1 \pm 0.5$ & $10.5 \pm 0.7$ \\
\hline Epinephrine & $11.5 \pm 0.6$ & $12.9 \pm 0.5$ \\
\hline$P=$ & 0.62 & 0.046 \\
\hline \multicolumn{3}{|c|}{$\begin{array}{l}\text { Renal Glucose Release } \\
\qquad\left(\mu \mathrm{mol} \cdot \mathrm{kg}^{-1} \cdot \mathrm{min}^{-1}\right)\end{array}$} \\
\hline Saline & $3.8 \pm 0.3$ & $2.8 \pm 0.1$ \\
\hline Epinephrine & $2.7 \pm 0.3$ & $5.2 \pm 0.5$ \\
\hline$P$ & 0.024 & 0.01 \\
\hline \multicolumn{3}{|c|}{$\begin{array}{l}\text { Hepatic Glucose Release } \\
\qquad\left(\mu \mathrm{mol} \cdot \mathrm{kg}^{-1} \cdot \mathrm{min}^{-1}\right)\end{array}$} \\
\hline Saline & $7.3 \pm 0.6$ & $7.7 \pm 0.6$ \\
\hline Epinephrine & $8.7 \pm 0.4$ & $7.8 \pm 0.9$ \\
\hline$P$ & 0.12 & 0.93 \\
\hline \multicolumn{3}{|c|}{ Renal Blood Flow (ml/min) } \\
\hline Saline & $1460 \pm 200$ & $1465 \pm 154$ \\
\hline Epinephrine & $1468 \pm 61$ & $1584 \pm 82$ \\
\hline$P=$ & 0.96 & 0.79 \\
\hline
\end{tabular}

${ }^{*}$ Mean of three determinations; ${ }^{\ddagger}$ mean of 150 - and 180 -min values.

one another and are collectively referred to as glucose turnover. Overall plasma glucose turnover averaged $11.4 \pm 0.5 \mu \mathrm{mol} \cdot$ $\mathrm{kg}^{-1} \cdot \mathrm{min}^{-1}$. Renal glucose release $\left(3.2 \pm 0.2 \mu \mathrm{mol} \cdot \mathrm{kg}^{-1} \cdot\right.$. $\min ^{-1}$ ) accounted for $27.8 \pm 2.1 \%$ of systemic glucose appearance (range $20.9-42.5 \%)$ while renal glucose uptake $(2.3 \pm 0.2$ $\mu \mathrm{mol} \cdot \mathrm{kg}^{-1} \cdot \mathrm{min}^{-1}$ ) accounted for $20.2 \pm 1.7 \%$ (range 13.4$31.0 \%$ ) of systemic glucose removal. Hepatic glucose release, calculated as the difference between overall plasma glucose appearance and renal glucose release, averaged $8.2 \pm 0.5 \mu \mathrm{mol}$ $\mathrm{kg}^{-1} \cdot \mathrm{min}^{-1}$ and accounted for $72.2 \pm 5.9 \%$ (range 57.5$79.1 \%$ ) of systemic glucose appearance.

Responses to epinephrine (Table IV, Figs. 1 and 2). Baseline measurements in volunteers infused with epinephrine were not significantly different from those infused with saline. During infusion of epinephrine, plasma epinephrine increased to $\sim 3,700 \mathrm{pmol} / \mathrm{liter}$ while values averaged less than $200 \mathrm{pmol} /$ liter in subjects infused with saline. Arterial glucose increased from $4.33 \pm 0.10$ to $6.32 \pm 0.49 \mathrm{mmol} / \mathrm{liter}(P<0.01)$ while in 


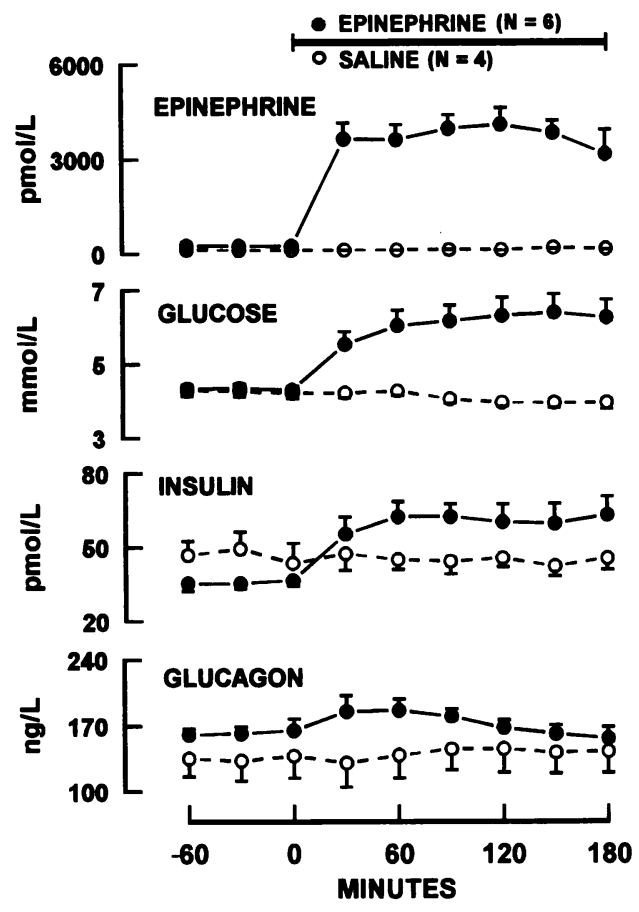

Figure 1. Arterial epinephrine, glucose, insulin, and glucagon concentrations during infusion of saline or epinephrine.

control saline infusions it did not change. There was a sustained increase in plasma insulin and a transient increase in plasma glucagon during epinephrine infusion whereas values for both hormones did not change during saline infusion.

Systemic glucose appearance during infusion of epinephrine increased to a peak within $60 \mathrm{~min}$ and subsequently decreased to rates during the last $30 \mathrm{~min}$ which were about $2.5 \mu \mathrm{mol} \cdot \mathrm{kg}^{-1}$. $\min ^{-1}$ above rates in control studies $(12.9 \pm 0.5$ vs $10.5 \pm 0.7$ $\left.\mu \mathrm{mol} \cdot \mathrm{kg}^{-1} \cdot \mathrm{min}^{-1}, P=0.046\right)$. Renal glucose release followed a similar pattern increasing to a peak within $60 \mathrm{~min}$ and then decreasing to rates during the last $30 \mathrm{~min}$ which were about $2.5 \mu \mathrm{mol} \cdot \mathrm{kg}^{-1} \cdot \min ^{-1}$ above rates observed in control experiments $\left(2.8 \pm 0.1\right.$ vs $5.2 \pm 0.5 \mu \mathrm{mol} \cdot \mathrm{kg}^{-1} \cdot \mathrm{min}^{-1}, P$ $=0.01)$. In contrast hepatic glucose release increased to a peak within $60 \mathrm{~min}$ and then decreased to rates during the last 30 min which were not significantly different from those in control experiments $\left(7.8 \pm 0.9\right.$ vs $\left.7.7 \pm 0.6 \mu \mathrm{mol} \cdot \mathrm{kg}^{-1} \cdot \mathrm{min}^{-1}\right)$. Consequently during the last $30 \mathrm{~min}$ of the epinephrine infusion, renal glucose release accounted for $40.3 \pm 5.5 \%$ of overall systemic glucose appearance, and the increase in renal glucose release accounted for essentially all of the increase in systemic glucose appearance.

\section{Discussion}

The present study demonstrates that in postabsorptive normal volunteers the kidney simultaneously takes up and releases appreciable amounts of glucose. Its release of glucose accounted for $20-42 \%$ (average $28 \pm 2 \%$ ) of all glucose released into the circulation and its uptake of glucose accounted for 13-31\% (average $20 \pm 2 \%$ ) of all glucose removed from the circulation. Moreover, infusion of epinephrine, which resulted in circulating concentrations similar to those observed during hypoglycemia

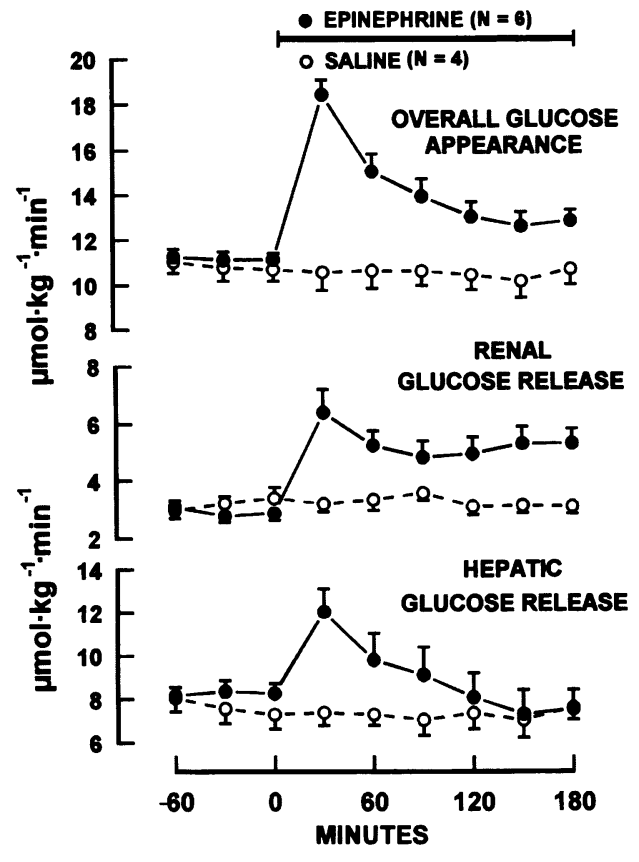

Figure 2. Overall glucose appearance, renal glucose release, and hepatic glucose release during infusion of saline or epinephrine

(30), caused a sustained increase in renal glucose release that by $3 \mathrm{~h}$ accounted for essentially all of the increased appearance of glucose in the circulation.

These observations challenge the current view (4-6) that the human kidney plays a minor role in glucose homeostasis. It must be appreciated however, that the current view is based on net balance measurements (7-10) which represent the difference between uptake and release of glucose by the kidney. Had we relied on mere net balance measurements, our baseline results would also have indicated a minor role for the kidney in postabsorptive glucose homeostasis. On the other hand, net balance measurements during the epinephrine infusion would have demonstrated an appreciable increase in net renal glucose output.

Our finding that renal glucose release accounts for $20-42 \%$ of systemic glucose release in the postabsorptive state is consistent with recent studies in dogs using similar techniques (18, 19). These observations and the response of the kidney to epinephrine suggest an important role of the kidney in glucose counterregulation and provide a possible explanation why people with chronic renal failure are prone to develop hypoglycemia (31). It has been demonstrated that hepatectomized-nephrectomized animals develop hypoglycemia more rapidly than hepatectomized animals (32-34).

Our finding that the human kidney is responsible for 13$31 \%$ of glucose removal from the circulation is also consistent with recent findings in dogs using similar techniques $(18,19)$. This uptake of glucose by the kidney in the postabsorptive state is comparable to that reported for skeletal muscle (35) and splanchnic tissues $(36,37)$. If uptake of glucose by the kidney were regulated by insulin in humans as it is in dogs and rats $(13,19,38)$, our observations could explain to some extent the insulin resistance found in patients with chronic renal failure (39) since loss of a major target organ for insulin could result in insulin resistance. 
Regarding the mechanism for renal glucose release, the normal human kidney does not contain appreciable glycogen stores (40). Moreover, renal cells which have appreciable glucose phosphorylating capacity and thus the ability to accumulate glycogen have relatively little glucose-6-phosphatase activity, whereas cells having little phosphorylating capacity possess abundant activity of glucose-6-phosphatase and other gluconeogenic enzymes $(13,41)$. It is thus likely that release of glucose by the kidney is due mainly if not exclusively to gluconeogenesis. Consistent with this conclusion is the fact that the reported net renal uptake of key gluconeogenic precursors (e.g. lactate, glycerol, glutamine and other amino acids) is sufficient to account for all of the release of glucose by the kidney observed in the present studies $(8-10)$.

In terms of net balance, the net output of glucose by the kidney $\left(<1 \mu \mathrm{mol} \cdot \mathrm{kg}^{-1} \cdot \mathrm{min}^{-1}\right)$ observed in the present study was small compared to that of the liver $\left(\sim 8 \mu \mathrm{mol} \cdot \mathrm{kg}^{-1}\right.$. $\left.\min ^{-1}\right)$. However, if gluconeogenesis were the predominant mechanism for renal glucose release, our results provide evidence that the kidney may be as important a gluconeogenic organ as the liver. For example, the best estimation at the present time indicates that about $30-40 \%$ of glucose appearance in plasma in normal postabsorptive humans is due to gluconeogenesis $(42,43)$. Our results indicate that the kidney accounts for $\sim 25 \%$ of all glucose released into the circulation. If all of this were due to gluconeogenesis and gluconeogenesis represented $40 \%$ of overall glucose appearance, the human kidney would be responsible for $>60 \%$ of gluconeogenesis. Since increased gluconeogenesis appears to be mainly responsible for the increased rate of appearance of plasma glucose in non-insulindependent diabetes mellitus $(44,45)$, it is of interest to note that kidneys of experimental diabetic rats exhibit increased output of glucose $(46,47)$ and increased activity of renal gluconeogenic enzymes (48).

In conclusion, the results of the present study indicate that in postabsorptive normal volunteers the kidney accounts for $>25 \%$ of all glucose appearing in the circulation and $\sim 20 \%$ of all glucose removed from the circulation and that renal release of glucose is stimulated by epinephrine at plasma epinephrine concentrations observed during hypoglycemia. These observations suggest an important role of the human kidney in glucose homeostasis.

\section{Acknowledgments}

We thank the staff of the University of Rochester General Clinical Research Center and the research volunteers; Dave Robson and William Peifer for their excellent technical help. We gratefully acknowledge the assistance of Dr. Dietrich Overkamp, Medizinische Klinik Tübingen, Germany, in the error estimation of the non-steady state.

The present work was supported in part by NIH/DRR/GCRC grants 5M01 RR 00044, NIDDK/DK-20411, 20579. Dr. Stumvoll is on leave from the Medizinische Klinik, Universität Tübingen, Germany, and is supported by a grant of the Deutsche Forschungsgemeinschaft DFG, Germany (Stu-192/1-2).

\section{References}

1. Schoolwerth, A. C., and K. Drewnowska. 1993. Renal metabolism. In Diseases of the kidney. R. W. Schrier and C. W. Gottschalk, editors. Little Brown and Company, Boston, Toronto, London. 233-260.

2. Schoolwerth, A. C., B. C. Smith, and R. M. Culpepper. 1988. Renal gluconeogenesis. Miner. Electrolyte Metab. 14:347-361.
3. Wirthensohn, G., and W. G. Guder 1986. Renal substrate metabolism. Physiol. Rev. 66:469-497.

4. Castellino, P., and R. A. DeFronzo. 1990. Glucose metabolism and the kidney. Semin. Nephrol. 10:458-463.

5. Steinberg, D. 1991. Regulation of carbohydrate metabolism. In Physiological Basis of Medical Practice. T. Satterfield, editor. Williams \& Wilkins, Baltimore. 728-739.

6. Felig, P., and M. Bergman. 1995. The endocrine pancreas: Diabetes mellitus. In Endocrinology and metabolism. P. Felig, J. D. Baxter, and L. A. Frohman, editors. McGraw-Hill, 1107-1250.

7. Aber, G. M., L. O. Morris, and E. Housley. 1966. Gluconeogenesis by the human kidney. Nature (Lond.). 212:1589-1590.

8. Björkman, O., P. Felig, and J. Wahren. 1980. The contrasting responses of splanchnic and renal glucose output to gluconeogenic substrates and to hypoglucagonemia in 60-h-fasted humans. Diabetes. 29:610-616.

9. Björkman, O., and P. Felig. 1982. Role of the kidney in the metabolism of fructose in 60-hour fasted humans. Diabetes. 31:516-520.

10. Brundin, T., and J. Wahren. 1994. Renal oxygen consumption, thermogenesis, and amino acid utilization during iv infusion of amino acids in man. Am. J. Physiol. 267:E648-E655.

11. Owen, O. E., P. Felig, A. P. Morgan, J. Wahren, and G. F. Cahill, Jr. 1969. Liver and kidney metabolism during prolonged starvation. J. Clin. Invest. 48:574-583.

12. Häussinger, D. 1990. Nitrogen metabolism in liver: structural and functional organization and physiological relevance. Biochem. J. 267:281-290.

13. Guder, W. G., and B. D. Ross. 1984. Enzyme distribution along the nephron. Kidney Int. 26:101-111.

14. Wolfe, R. R. 1992. Radioactive and stable isotope tracers in biomedicine. John Wiley \& Sons, New York. 122 pp.

15. Consoli, A., N. Nurjhan, J. J. Reilly, Jr, D. M. Bier, and J. E. Gerich. 1990. Contribution of liver and skeletal muscle to alanine and lactate metabolism in man. Am. J. Physiol. 259:E677-E685.

16. Stanley, W., E. Gertz, J. Wisneski, R. Neese, D. Morris, and G. Brooks. 1986. Lactate extraction during net lactate release in legs of humans during exercise. J. Appl. Physiol. 60:1116-1120

17. McGuinness, O. P., T. Fugiwara, S. Murrell, D. Bracy, D. Neal, D. O'Connor, and A. D. Cherrington. 1993. Impact of chronic stress hormone infusion on hepatic carbohydrate metabolism in the conscious dog. Am. J. Physiol. 265:E314E322.

18. Cersosimo, E., R. L. Judd, and J. M. Miles. 1994. Insulin regulation of renal glucose metabolism in conscious dogs. J. Clin. Invest. 93:2584-2589.

19. Cherrington, A. D., D. H. Wasserman, and O. P. McGuinness. 1994. Renal contribution to glucose production after a brief fast: fact or fancy? J. Clin. Invest. 93:2303.

20. World Health Organization Expert Committee. 1980. Second report on diabetes mellitus. Technical Report Series, Geneva, Switzerland. No. 646 pp.

21. Brooks, D., M. Black, T. Arcangeli, T. Aoki, and D. Wilmore. 1989. The heated dorsal hand vein: an alternative arterial sampling site. J. Parenter. Enteral. Nutr. 13:102-105.

22. Nurjhan, N., F. Kennedy, A. Consoli, C. Martin, J. Miles, and J. Gerich. 1988. Quantification of the glycolytic origin of plasma glycerol: Implications for the use of the rate of appearance of plasma glycerol as an index of lipolysis in vivo. Metabolism. 37:386-389.

23. Herbert, V., K. Lau, C. Gottlieb, and S. Bleicher. 1965. Coated charcoal immunoassay of insulin. J. Clin. Endo. \& Metab. 25:1375-1384

24. Cryer, P., J. Santiago, and D. Shah. 1974. Measurement of norepinephrine and epinephrine in small volumes of human plasma by a single isotope derivative method: response to the upright posture. J. Clin. Endo. \& Metab. 39:1025-1029.

25. Brun, C. 1951. A rapid method for the determination of para-aminohippuric acid in kidney function tests. J. Lab. Clin. Med. 37:955-958.

26. Earle, D. P., Jr., and R. W. Berliner. 1946. A simplified clinical procedure for measurement of glomerular filtration rate and renal plasma flow. Proc. Soc. Exp. Biol. Med. 62:262-264.

27. DeBodo, R., R. Steele, N. Atszuler, A. Dunn, and J. Bishop. 1963. On the hormonal regulation of carbohydrate metabolism: studies with $\mathrm{C} 14$ glucose. Rec. Prog. Horm. Res. 19:445-488.

28. Cobelli, C., A. Mari, and E. Ferrannini. 1987. Nonsteady-state error analysis of Steele's method and developments for glucose kinetics. Am. J. Physiol. 252:E679-E689.

29. Dinneen, S., J. Gerich, and R. Rizza. 1992. Carbohydrate metabolism in noninsulin-dependent diabetes mellitus. N. Engl. J. Med. 327:707-713.

30. Mitrakou, A., C. Ryan, T. Veneman, M. Mokan, T. Jenssen, I. Kiss, J. Durrant, P. Cryer, and J. Gerich. 1991. Hierarchy of thresholds for activation of counterregulatory hormone secretion, symptoms, and cerebral dysfunction. Am. J. Physiol. 260:E67-E74.

31. Owen, R. 1989. Hypoglycemia associated with renal failure. Endocrinol. Metab. Clin. North Am. 18:103-121.

32. Bergman, H., and D. R. Drury. 1938. The relationship of kidney function to the glucose utilization of the extra abdominal tissues. Am. J. Physiol. 124:279284. 
33. Cohn, C., and M. Kolinsky. 1949. Effect of blood sugar levels and insulin lack on gluconeogenesis by the kidney of the dog. Am. J. Physiol. 156:345-348.

34. Mackler, B., P. Ammentorp, H. Graubarth, and G. M. Guest. 1951. Glucose formation by kidneys in eviscerated dogs. Proc. Soc. Exp. Biol. Med. 78:479480.

35. Kelley, D., A. Mitrakou, H. Marsh, F. Schwenk, J. Benn, G. Sonnenberg, M. Archangeli, T. Aoki, J. Sorensen, M. Berger, P. Sonksen, and J. Gerich. 1988. Skeletal muscle glycolysis, oxidation, and storage of an oral glucose load. J. Clin. Invest. 81:1563-1571.

36. Mari, A., J. Wahren, R. A. DeFronzo, and E. Ferrannini. 1994. Glucose absorption and production following oral glucose: Comparison of compartmental and arteriovenous-difference methods. Metabolism. 43:1419-1425.

37. DeFronzo, R., E. Ferrannini, R. Hendler, R. Felig, and J. Wahren. 1983. Regulation of splanchnic and peripheral glucose uptake by insulin and hyperglycemia in man. Diabetes. 32:35-45.

38. Gregg, C. M., J. J. Cohen, A. J. Black, M. A. Espeland, and M. L. Feldstein. 1978. Effects of glucose and insulin on metabolism and function of perfused rat kidney. Am. J. Physiol. 235:F52-F61.

39. DeFronzo, R., A. Abnestrand, D. Smith, R. Hendler, and J. Wahren. 1981. Insulin resistance in uremia. J. Clin. Invest. 67:563-568.

40. Biava, C., A. Grossman, and M. West. 1966. Ultrastructural Observations on Renal Glycogen in Normal and Pathologic Human Kidneys. Lab. Invest. 15:330-356.
41. Burch, H. B., R. G. Narins, C. Chu, S. Fagioli, S. Choi, W. McCarthy, and O. H. Lowry. 1978. Distribution along the rat nephron of three enzymes of gluconeogenesis in acidosis and starvation. Am. J. Physiol. 235:F246-F253.

42. Landau, B. R., J. Wahren, V. Chandramouli, W. Schumann, K. Ekberg, and S. C. Kalhan. 1995. Use of $2 \mathrm{H} 2 \mathrm{O}$ for estimating rates of gluconeogenesis. J. Clin. Invest. 95:172-178.

43. Consoli, A., F. Kennedy, J. Miles, and J. Gerich. 1987. Determination of Krebs cycle metabolic carbon exchange in vivo and its use to estimate gluconeogenesis in man. J. Clin. Invest. 80:1303-1310.

44. Consoli, A., N. Nurjhan, F. Capani, and J. Gerich. 1989. Predominant role of gluconeogenesis in increased hepatic glucose production in NIDDM. Diabetes. 38:550-561.

45. Magnusson, I. D. Rothman, L. Katz, R. Shulman, and G. Shulman. 1992. Increased rate of gluconeogenesis in type II diabetes. A 13C nuclear magnetic resonance study. J. Clin. Invest. 90:1323-1327.

46. Kida, K., S. Nakago, F. Kamiya, Y. Toyama, N. Takashi, and H. Nakagawa. 1978. Renal net glucose release in vivo and its contribution to blood glucose in rats. J. Clin. Invest. 62:721-726.

47. Lemieux, G., M. Achkar, P. Vinay, and A. Gougourx. 1982. Characteristics of ammoniagenesis and glyconeogenesis by the diabetic kidney in vitro studies in the rat. Contrib. Nephrol. 31:23-28.

48. Lemieu, G., M. Arbda, P. Fournel, and C. Lemieu. 1984. Renal enzymes during experimental diabetes mellitus in the rat. Role of insulin, carbohydrate metabolism and ketoacidosis. Can. J. Physiol. Pharmacol. 31:70-75. 